\title{
Estudo morfométrico e morfológico da cicatrização após uso do laser erbium:YAG em tecidos cutâneos de ratos
}

\section{Morphometrical and morphological study of cicatricial effects caused by application of laser erbium:YAG on the skin of rats}

Lúcia de Noronha'; Eduardo Wei Kin Chin²; Letícia Yurie Kimura²; Ruth Graf ${ }^{3}$

\begin{abstract}
unitermos resumo
Este trabalho analisa o efeito da reparação cutânea do laser erbium:yttrium aluminunn garnet (YAG) Ratos (Er:YAG) em pele de ratos através de estudo histológico e morfométrico. Tatuaram-se duas figuras no dorso de cada animal ( $n=35$ ), denominadas controle e experimento. Na figura experimento, apli-

Fibroplasia caram-se três passadas de laser Er:YAG com parâmetros padronizados. Cinco animais foram eutanasiados nos dias $0,7,14,28,56,84$ e 112 de pós-operatório. O estudo histológico demonstrou no dia 0 dano de ablação médio de 215,24 micrômetros $(\mu \mathrm{m})$, sendo homogêneo com vaporização da epiderme e porções superficiais da derme. O dano térmico residual foi pequeno (média de 41,45 $\mu \mathrm{m}$ ), observando-se áreas onde estava praticamente ausente. A fibroplasia cicatricial já estava presente no dia 7 (média de

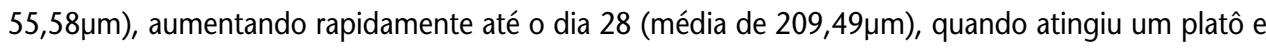
se manteve até o dia 112. Não houve sinais de processo inflamatório agudo no dia 7 e a reepitelização já estava completa. Concluiu-se que a aplicação de laser na pele de ratos induz reparação cutânea ao longo de 112 dias nas condições do experimento.
\end{abstract}

This study analyses the skin contracture effect of the erbium:YAG (Er:YAG) laser on the skin of rats by light microscopic histological and morphometrical evaluations. Two squares of back skin were precision tattooed on each of the animals $(\mathrm{n}=35)$, that were termed control and experimental skin. The experimental skin was treated with three passes of the Er:YAG laser with standardized parameters. Five animals were killed and skin specimens were analyzed at 00,07, 14, 28, 56, 84 and 112 days. Histologic examination demonstrated a mean of 215.24 micrometers ablative damage that was homogeneous with complete vaporization of the epidermis and superficial dermis. The residual thermal damage was small (mean of 41.45 micrometers) observing areas where it was absent. The cicatritial fibroplasy was present at day 07 (mean 55.58 micrometers) rising quickly until day 28 (mean of 209.49 micrometers) when it reaches a plateau and maintaining it until day 112. There are no signs of acute inflammatory process at day 07 and the reepithealization was complete at this day. This study revealed that the laser had induced shortening of the treated areas which persisted beyond the 112 days.

1. Professora-adjunta da Pontifícia Universidade Católica do Paraná (PUC/PR); doutora em Patologia.

2. Acadêmicos de Medicina da PUC/PR.

3. Doutora em Cirurgia Plástica; titular da Sociedade Brasileira de Cirurgia Plástica.

Trabalho realizado no Laboratório de Patologia Experimental da PUC/PR 


\section{Introdução}

O resurfacing facial sofreu avanços nos últimos anos com o aparecimento do laser de dióxido de carbono $\left(\mathrm{CO}_{2}\right)$, cujos resultados se tornaram superiores aos peelings químicos $\mathrm{e}$ à dermoabrasão, especialmente nos pacientes que apresentam rugas profundas. Estes resultados difundiram seu uso, embora o laser de $\mathrm{CO}_{2}$ cause significativa morbidade, como o prolongado tempo de recuperação e eritema persistente, além de hipo ou hiperpigmentação temporárias ou permanentes. A morbidade e os efeitos colaterais deste método têm estimulado a procura de métodos alternativos de remodelação cutânea ${ }^{(6,33)}$.

O laser Erbium:YAG (Er:YAG), lançado comercialmente em 1996, tem dez vezes maior capacidade de absorção pela água quando comparado ao laser $\mathrm{CO}_{2}$. Uma vez que a capacidade de penetração ótica do laser é inversamente proporcional a sua capacidade de absorção pela água, a profundidade de penetração ótica do laser Er:YAG é dez vezes menor do que a do $\mathrm{CO}_{2}$. Esta alta capacidade de absorção pela água confere a este laser uma capacidade de dano de ablação (DA) maior, mais precisa e acurada, sendo que a baixa penetração tecidual the confere baixa difusão do calor, causando, assim, menor dano térmico residual (DTR). $\mathrm{O}$ laser $\mathrm{CO}_{2}$ proporciona maior DTR quando comparado ao Er:YAG, pois o DTR é o resultado do aquecimento exagerado dos tecidos cutâneos pelo laser $\mathrm{CO}_{2}$, devido a sua alta capacidade de penetração tecidual e difusão do calor. Além disso, mais passadas do Er:YAG são necessárias para alcançar a mesma profundidade de DA alcançada pelo laser $\mathrm{CO}_{2}$, porém, por causar menos DTR, o Er:YAG permite controle mais preciso da profundidade de lesão $(1,17,19,21,33,41,42)$

Segundo alguns autores, o efeito fotomecânico do laser Er:YAG resulta em menor índice de complicações pós-operatórias quando comparado ao do laser $\mathrm{CO}_{2}$. Em contrapartida, o Er:YAG resulta em hemostasia menos efetiva com menor contração do colágeno. $\mathrm{O} \mathrm{CO}_{2}$ e seu efeito fototérmico causam maiores complicações pós-operatórias. Em contrapartida, causam hemostasia mais efetiva e maior contração do colágeno ( $25 \%$ durante a irradiação contra apenas $2 \%$ do laser Er:YAG) ${ }^{(2,26)}$.

Poucos estudos na literatura avaliaram os efeitos histológicos da aplicação do laser Er:YAG em tecidos cutâneos. Em vista disso, o objetivo deste estudo foi avaliar as alterações histopatológicas e morfométricas na pele de ratos submetidos à aplicação do laser Er:YAG ${ }^{(8,23,42)}$.

\section{Método}

Utilizaram-se 35 ratos machos, com idade variando entre 100 e 120 dias de vida, com peso entre $250 \mathrm{~g}$ e $300 \mathrm{~g}$, da linhagem Wistar. Os animais foram divididos aleatoriamente em sete grupos de cinco animais cada (G1 a G7).

Sob anestesia inalatória com éter etílico a $100 \%$, cada animal foi posicionado em decúbito ventral para realização da tricotomia de toda a região dorsal, seguida de antisepsia local com solução de polivinilpirrolidona-iodo e da tatuagem de uma figura quadrangular de $2,2 \times 2,2 \mathrm{~cm}$ na mesma região.

Foi utilizado um aparelho de laser Er:YAG (Erbium: Yttrium Aluminum Garnet da ESC Medical Systems Ltd., Yokneam Industrial Park, Israel), que produz radiação infravermelha com comprimento de onda de $2.940 \mathrm{~nm}$ e com um coeficiente de absorção pela água de $12.800 \mathrm{~cm}^{-1}$. O aparelho de laser foi regulado nos seguintes parâmetros de tela: 1,5J de energia, 1,7W de potência, $3 \mathrm{~mm}$ de tamanho do ponto do laser, sobreposição de $30 \%$, formato quadrado, tamanho 10 eângulo 0 . Estes parâmetros fornecem fluência de $21,4 \mathrm{~J} / \mathrm{cm}^{2}$ ou densidade de energia equivalente ${ }^{(19,21)}$.

Foram realizadas três passadas deste laser na área previamente tatuada. Manteve-se o curativo pós-operatório aberto e com aplicação de fina camada de vaselina creme.

Os grupos de cinco animais foram eutanasiados nos seguintes dias: G1 no dia 0, G2 no dia 7, G3 no dia 14, G4 no dia 28, G5 no dia 56, G6 no dia 84 e G7 no dia 112.

Durante todo o pós-operatório os animais foram acompanhados clinicamente. Em seguida, amostras cirúrgicas da área previamente tatuada foram retiradas e encaminhadas para estudos histológicos e morfométricos. Um fragmento retangular com $0,5 \times 2 \mathrm{~cm}$ foi ressecado de cada animal, sendo que cada fragmento continha área central lesada e área periférica de pele não-lesada que foi usada como controle. As peças foram fixadas em formol a $10 \%$ e, após 72 horas, o material foi submetido a processamento para preparo das lâminas. O material foi então seccionado ao longo de seu maior eixo, obtendo-se dois fragmentos de pele com $0,5 \times 1 \mathrm{~cm}$, os quais foram processados conforme técnicas convencionais e incluídos em blocos de parafina, de modo que a face dermoepidérmica ficasse voltada para a superfície de corte do bloco. Foi obtido um bloco de parafina de cada animal do experimento, todos contendo dois fragmentos. Para cada bloco foram cortadas três lâminas de $4 \mu \mathrm{m}$, as quais foram coradas 
em hematoxilina-eosina (para análise do processo inflamatório na fase G1), elástica de Weigert (para avaliação de fibras elásticas) e tricrômico de Mallory (para avaliação de fibras colágenas). Os seguintes parâmetros morfométricos, todos medidos em micrômetros $(\mu \mathrm{m})$, foram avaliados:

Dano de ablação (DA) - O DA foi calculado medindo-se a distância da camada granulosa da epiderme até a transição da derme com o músculo estriado esquelético dorsal do rato na pele controle (espessura da pele controle $=E P C$ ) e subtraindo a EPC da espessura da pele lesada (EPL), medida pela distância da porção mais superficial da pele lesada até a transição da derme com o músculo estriado esquelético dorsal do rato. Foram realizadas 30 medidas em cada uma das lâminas coradas em hematoxilina-eosina, sendo que em cada fragmento foram feitas 15 medidas. Esta análise foi realizada somente nos animais do grupo G1. DA = EPC - EPL.

Dano térmico residual (DTR) - O DTR foi calculado medindo-se a distância da porção mais superficial da pele residual na área aplicada até a última fibra colágena com degeneração basofílica (transição entre o colágeno dérmico lesado e o íntegro). Foram obtidas 30 medidas em cada uma das lâminas coradas em tricrômico de Mallory, sendo 15 medidas em cada fragmento da lâmina. Esta avaliação foi realizada somente nos animais do grupo G1.

Espessura da fibroplasia (EF) - Definida pela área de neoformação colágena presente na pele lesada pelo laser. Foram realizadas 30 medidas em cada uma das lâminas coradas em tricrômico de Mallory, sendo 15 medidas em cada fragmento da lâmina. Esta avaliação foi feita somente nos animais do grupo G2, G3, G4, G5, G6 e G7.

Foram excluídas as medidas em que se encontrou artefato técnico ou próximas a folículos pilosos.

\section{Resultados}

A observação clínica dos animais mostrou ablação completa da epiderme com sangramento puntiforme logo após a aplicação do laser, além de ausência de debris e eritema homogêneo sobre a derme remanescente. Até o terceiro dia do experimento houve um aumento progressivo do edema com aparecimento de secreção seroemática que persistiu até o quinto dia, sofrendo ressecamento e se transformando em crosta, que por sua vez caiu espontaneamente ao sétimo dia do experimento, deixando à vista epiderme brilhante e eritematosa. A hiperemia da epiderme jovem perma- neceu até o décimo dia do experimento quando houve aparecimento de pêlos novos.

Observamos nas Figuras 1 e 2 que o grupo G1, sacrificado logo após a aplicação do laser, apresentava a epiderme e as porções mais superficiais da derme papilar totalmente vaporizadas, ou seja, ausentes, efeito conhecido como dano de ablação (DA). Além disso, o restante da derme papilar e as porções superficiais da derme reticular se apresentavam necrosadas e coaguladas, efeito conhecido como dano térmico residual (DTR).

As Figuras $\mathbf{3}$ a $\mathbf{8}$ demonstram a pele já reepitelizada e o processo de fibroplasia (EF) progressiva que se instala na derme superficial lesada pelo laser com 7, 14, 28, 56, 84 e 112 dias de evolução.

A Figura 9 demonstra as médias das medidas do DA no grupo G1. O valor médio de todos os animais em conjunto é colocado abaixo do gráfico.

A Figura 10 apresenta a avaliação do DTR neste mesmo grupo.

Na Figura 11 são demonstradas as médias das medidas da EF em diferentes períodos do pós-operatório.

\section{Discussão}

$\mathrm{O}$ animal mais utilizado em estudos experimentais dos efeitos do laser na pele é o porco, pois apresenta grande analogia com a estrutura, espessura e cicatrização da pele humana. Entretanto, deve-se considerar o grande porte destes animais e as dificuldades decorrentes de sua obtenção, manipulação e manutenção. O rato da linhagem Wistar é um animal de pequeno porte, com maior facilidade de manipulação experimental, pequena morbidade e mortalidade. Porém, a pele dos ratos não apresenta uma divisão clara entre a derme papilar e a reticular nos métodos histológicos convencionais, como é observado na pele de humanos. Em vista disso, métodos que utilizam estes compartimentos anatômicos para comparar a profundidade das lesões podem ser falhos e pouco reprodutíveis ${ }^{(5,18)}$. Outra diferença importante é a quantidade de fibras elásticas encontradas na derme, que é bem menor nos ratos do que nos humanos. Isto pode ser importante em estudos experimentais que visam a processos de cicatrização, como neste experimento. Em relação aos efeitos de dano de ablação (DA) e dano térmico residual (DTR) após a aplicação do laser, os modelos experimentais se mostram apenas adequados, porém não totalmente comparáveis com aqueles vistos em pele humana. Isto porque, como 


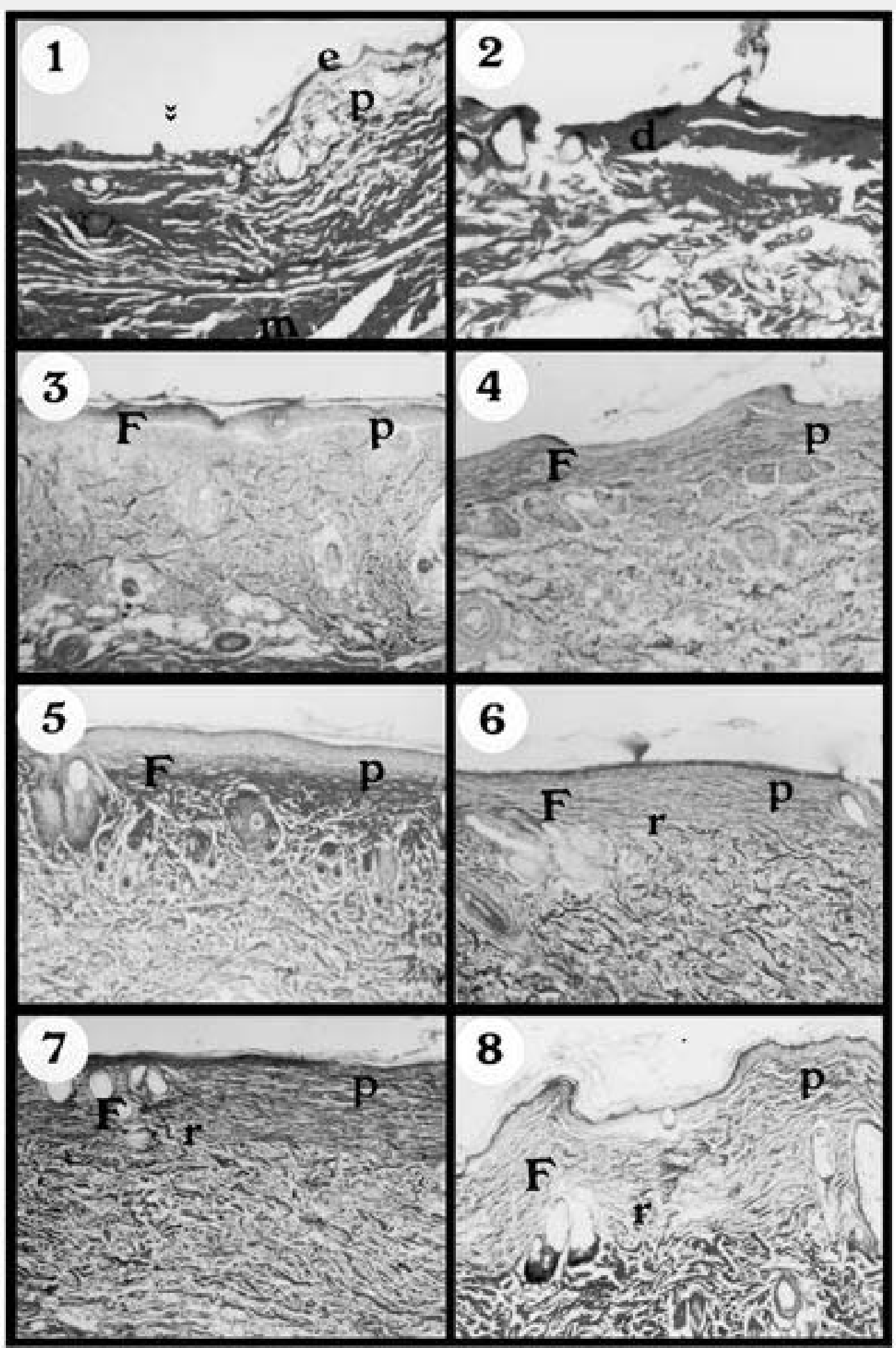

Figuras 1 a 8 - As Figuras 1 e 2 foram retiradas de animais do grupo G1, sacrifício no dia 0. As Figuras 3 a 8 foram retiradas de animais dos grupos G2, G3, G4, G5, G6 e G7, respectivamente, compreendendo os dias 7, 14, 28, 56 e 84 de sacrifício. As Figuras 1, 3, 4, 5, 6, 7 e 8 foram capturadas com aumento de 100x. Somente a Figura 2, que é um detalhe da 1, foi capturada com aumento de 400x. As Figuras 1, 2, 4 e 5 estão coradas pela elástica de Weigert e as Figuras de números 3, 6, 7 e 8 pelo tricrômico de Mallory (e = epiderme, $p=$ derme papilar, $r=$ derme reticular, $m=$ músculo estriado esquelético dorsal, $d=D T R, F=$.broplasia $e>>=D A)$. Na Figura 1 observa-se dano de ablação (>) que é representado pela ausência completa da epiderme (e) e da derme papilar (p) quando se compara com a porção não-lesada da pele. Na Figura 2 (detalhe da Figura 1) observa-se o dano térmico residual (d) representado por faixa de tecido compacto e homogêneo em vermoelho-escuro. As Figuras 3 a 8 devem ser analisadas comparativamente onde a fibroplasia (F) representada por faixa colágena vai progressivamente aumentando. Observe que na Figura 3 a fibroplasia compromete apenas a derme papilar (p). Já nas Figuras 4 e 5 a fibroplasia $(F)$ compromete derme papilar (p) e porções superficiais da derme reticular ( $r$ ). Se analisarmos as Figuras 6, 7 e 8, observamos que a fibroplasia ( $F$ ) atinge a derme papilar (p) e toda a porção superficial da derme reticular (r), indo até a derme reticular média na Figura 8. 


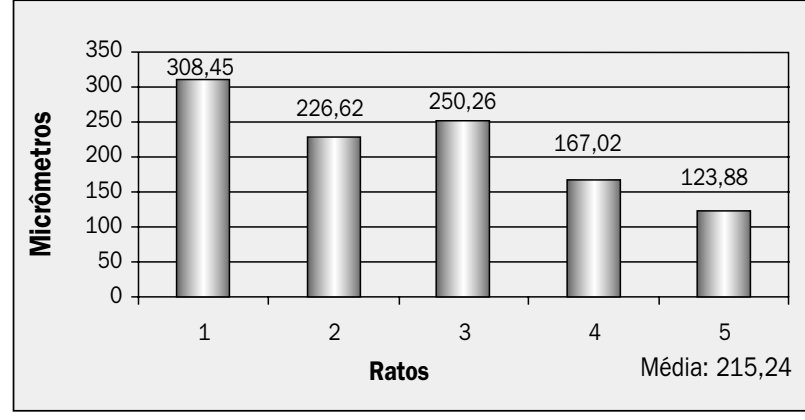

Figura 9 - Médias das medidas do DA no dia zero do pós-operatório. 0 valor médio de todos os animais em conjunto é colocado abaixo do gráfico

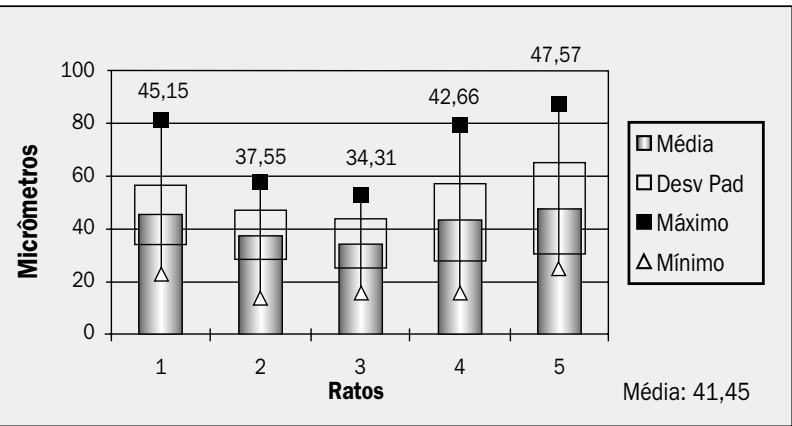

Figura 10 - Avaliação do DTR no pós-operatório imediato. 0 valor médio de todos os animais em conjunto é colocado abaixo do gráfico

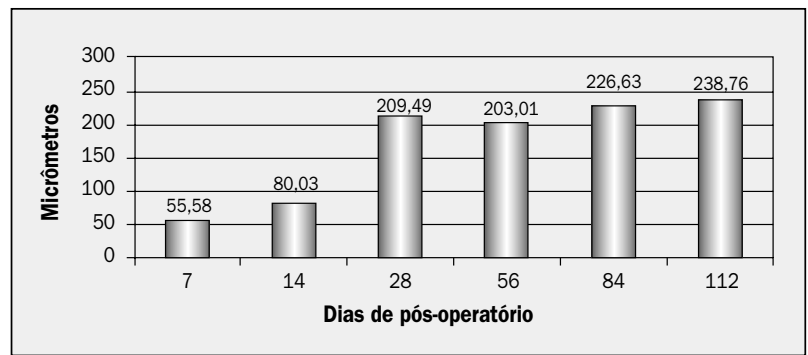

Figura 11 - Médias das medidas da EF em diferentes períodos de pós-operatório

para os lasers aplicados em resurfacing facial, o cromóforo-alvo é a água, o variado conteúdo hídrico cutâneo entre as espécies propicia efeitos de DA e de DTR diferentes $^{(3,5,6,13,14,18,21,30,33,34,36,38,41-44) \text {. }}$

Todos os animais do experimento apresentaram cicatrização completa até o sétimo dia do experimento, como observado em porcos, por outros autores, que referem uma cicatrização mais rápida com o laser de Er:YAG que com outros tipos de lasers. Nos dois primeiros dias do processo inflamatório inicial ocorre o edema dos tecidos lesados com a formação de secreção seroemática que se transforma em crosta pelo ressecamento dos tecidos em contato com o ar. Esta crosta seroemática é formada por neutrófilos e fibrina. Esta crosta recobre a área de degeneração do colágeno conhecida como dano térmico residual (DTR), como de- monstra a Figura 2, a qual vai ser removida pelo processo inflamatório e posteriormente substituída por neoformação colágena conhecida como fibroplasia (FE) como pode ser visto nas Figuras 3 a $8^{(20,21,26,27)}$.

A grande vantagem da avaliação morfométrica do DA e do DTR é sua precisão e confiabilidade, pois ela é feita utilizando como controle a pele imediatamente adjacente à área lesada, minimizando os efeitos de diferenças de espessura da pele de região para região. Uma desvantagem está no cálculo do DA, pois ele é feito através da subtração entre a espessura da pele controle e a espessura da pele lesada (DA = EPC - EPL). Com isso, se alguma modificação anatômica ou fisiológica ocorrer na pele lesada pelo laser, isto poderia influenciar na medida da EPL e, conseqüentemente, no valor final do DA. A aplicação do laser provoca um tipo de lesão de origem física, através do calor, provocando ablação com desnudamento da epiderme e exposição da derme (DA), além de desnaturação protéica com necrose de coagulação do colágeno dérmico (DTR). Estas lesões provocam o desencadeamento dos mecanismos de reação inflamatória, sendo os primeiros sinais a congestão, manifestada clinicamente pelo eritema, e edema dos tecidos lesados. Em vista disto há um aumento de volume da área onde foi aplicado o laser e conseqüentemente um aumento da EPL. Sendo assim, como o DA = EPC - EPL, o DA final, medido e calculado por este método, ficaria menor que o real. Todas estas alterações inflamatórias ocorrem já nos primeiros segundos após o tecido ter sofrido a injúria. Portanto, mesmo que a coleta e fixação do material sejam realizadas imediatamente após o procedimento cirúrgico, como foi feito no grupo $\mathrm{G} 1$ deste experimento, é impossível evitar um certo grau de edema e congestão, dificultando assim o cálculo do DA. A dificuldade em se calcular o DA por métodos morfométricos está justamente no seu conceito, pois ele representa os tecidos que foram vaporizados pela ação do laser através do calor. Em vista disso, não há como medi-lo diretamente, tendo-se que lançar mão de métodos indiretos. Outros métodos já foram utilizados, como, por exemplo, o uso de balanças analíticas para pesar a pele antes e depois do uso do laser. Porém este método esbarra no mesmo problema do método morfométrico, pois o edema e a congestão também aumentam o peso da pele lesada ${ }^{5}$, $30,14,35,31,32,36)$.

Outro problema a ser contornado é que o DA e o DTR não são homogêneos ao longo de toda a lesão, por isso é necessário evitar medidas morfométricas nas porções mais periféricas da lesão, onde as alterações não são muito expressivas. As áreas de artefatos téc- 
nicos também devem ser evitadas, pois não permitem medidas morfométricas seguras. Os artefatos técnicos são um problema com este material, pois a área superficial de colágeno coagulado presente nas lesões, a qual representa justamente o DTR, é mais endurecida, de difícil fixação, processamento e corte, inviabilizando, por vezes, alguns preparados histológicos. As áreas próximas a folículos pilosos possuem DA e DTR menores e devem, portanto, ser evitadas, também, durante o processo morfométrico ${ }^{(5,30,14,35,31,32,36)}$.

O DA comprometeu toda a epiderme, a derme papilar e porções superficiais da derme reticular (Figura 1). Estas alterações já foram observadas em outros estudos. Nossos resultados são, portanto, muito semelhantes aos relatados na literatura revisada. Houve também homogeneização do colágeno da derme reticular superficial e perda da sua afinidade tintorial à hematoxilina-eosina, bem como aos outros corantes utilizados no tricrômico de Mallory e na elástica de Weigert, o que caracteriza o DTR. O DTR apresentou zona de coagulação (ZC) completa do colágeno que se mostrava fortemente basofílica, não sendo possível individualizar as suas fibras, e zona de transição (ZT) definida como a área onde as fibras colágenas não estão completamente lesadas. Neste estudo a ZT apresentou fibras colágenas eosinofílicas, edemaciadas e, por vezes, homogeneizadas, com fibroblastos tumefeitos e núcleos picnóticos. Estes achados também já foram corroborados por outros estudos revisados ${ }^{15,} 16$, $22,43,45)$.

Um padrão lesional muito interessante foi encontrado nas áreas contendo pêlos. Estas áreas apresentam menor profundidade de DA e DTR, sugerindo que o pêlo pode servir como estrutura protetora. O laser Er:YAG utiliza a água como cromóforo principal para que possa ser absorvido e realizar, assim, os seus efeitos sobre a pele. Como a haste do pêlo possui pouca água, pois é constituída de queratina, os raios do laser não são absorvidos por esta estrutura, e sim transmitidos, refletidos ou difundidos. Isto poderia explicar a minimalização dos seus efeitos nas áreas que continham pêlos $(3,9,10,11,12,19)$. Os ratos são animais com o dorso altamente piloso, o que poderia ter um efeito protetor não observado em humanos.

Não houve reação inflamatória do tipo celular nas áreas de lesão. Porém havia sinais iniciais de atividade inflamatória como edema e congestão vascular. Vale lembrar que o ede-

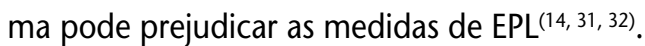

Os valores de EPC e EPL e sua variação de forma semelhante ao longo dos retalhos $(p<0,05)$ só vêm confirmar que a fórmula utilizada para o cálculo do DA neste estudo pode ser fidedigna, pois tanto a média da EPL como da EPC variam na mesma proporção, sugerindo não haver vícios de amostragem ou de leitura. $\mathrm{O}$ edema que ocorreu nas áreas lesadas poderia atrapalhar, mas, como sugerem as médias gerais da EPL, sempre menores que as da EPC, ele não influenciou de maneira significativa no cálculo do DA, embora tenhamos consciência de que o valor final do DA possa ser menor que o real neste estudo $(5,14,30,31,32)$.

Os valores finais de DA podem ser observados na Figura 9, sendo que a média foi de $215,24 \mu \mathrm{m}$ $(p<0,05)$. Embora em modelos experimentais diferentes, estes valores já foram obtidos como resultado de outros

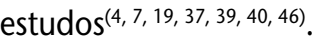

Como já foi explicado, o DTR apresenta duas zonas bem definidas à histologia: a ZC e a ZT. Neste estudo, somente a ZC foi medida, pois esta sim apresenta limites bem definidos. O valores de DTR podem ser observados na Figura 10 , sendo que a média foi de $41,45 \mu \mathrm{m}$. Estes valores aproximam-se dos resultados de outros estudos, muito embora não sejam os mesmos modelos experimentais ${ }^{(4,7}$, $8,19,24,25,29,33,37,39,40,46)$

O DA é responsável pela retirada do colágeno lesado pelos raios UV, e o DTR produz reação inflamatória a fim de limpar a área que apresenta os tecidos desvitalizados. Esta reação inflamatória suscita a neocolagenização que é responsável, em adição à retirada do colágeno lesado pelo sol, pela aparência mais jovem da pele. O resultado ideal na derme é que haja grande migração de fibroblastos e neoformação de fibras colágenas, com a conseqüente formação de uma faixa de fibroplasia, responsável, em última instância, pelo aspecto mais jovem da pele, efeito clínico este que se deseja obter com o procedimento de resurfacing a laser. Em vista disso, nenhuma das alterações causadas pelo laser é dispensável nos processos de resurfacing. Porém, o DTR excessivo é responsável por pós-operatório mais longo e com maiores complicações, pois causa mais reação inflamatória e conseqüentemente, cicatrizes ${ }^{(4,7,8,19}$, $24,25,29,33,37,39,40,46)$.

Em nosso experimento, após a cicatrização completa, a partir do décimo dia, os pêlos cresceram normalmente e a pele se tornou de aspecto normal, apenas apresentando leve eritema. Já no $14^{\circ}$ dia, os animais revelaram uma aparência normal da epiderme ${ }^{(24,26-29)}$.

Do ponto de vista morfológico, foi observado a partir do sétimo dia (grupo G2) um espessamento da derme papilar à custa de neoformação colágena que se manteve até o dia 
28 (grupo G3) quando a neocolagenização alcançou o seu máximo. No início o colágeno é imaturo, isto é, com grande quantidade de fibroblastos jovens e fibras colágenas menos densas devido à grande quantidade de água que possuem. Com o passar do tempo o colágeno amadurece. Este fato pôde ser comprovado quando foram observados os animais do dia 56 (grupo G4) já com maior quantidade de colágeno maduro, o qual é menos celular e com menor quantidade de água. A partir daí (grupo G5 a G7) o tecido conjuntivo vai amadurecendo progressivamente com maior deposição de colágeno maduro, o qual é responsável pelo espessam ento das áreas lesadas pelo laser no período de cicatrização(20, 24).
Na Figura 11 nós observamos que a área de fibroplasia aumentou rapidamente até o dia 28 (G3) devido à grande produção de tecido colágeno jovem, como já foi explicado anteriormente. A partir do dia 28 (G3) a fibroplasia se manteve num platô, provavelmente porque parou a produção de fibras colágenas jovens e se iniciou a maturação do colágeno já presente ${ }^{(20,24)}$.

Como conclusão deste estudo pudemos constatar que o laser Er:YAG provoca extenso DA e pequeno DTR, conduzindo a uma progressão rápida do processo de cicatrização com reepitelização completa da epiderme, ausência de processo inflamatório agudo e presença de fibroplasia já no dia 7 do experimento.

\section{Referências}

I. ADRIAN, R. M. Pulsed carbon dioxiode and erbium-YAG laser resurfacing: a comparative clinical and histologic study.J Cutan LaserTher, n. I, p. 29-35, 1999.

2. ALSTER,T.S. Cutaneous resurfacing with $\mathrm{CO} 2$ and Erbium:YAG lasers: preoperative, intraoperative, and postoperative considerations. Plast Reconstr Surg, v. 103, p. 619-34, 1999 (2).

3. ANDERSON, R. R. Optics of the skin. In: LIM, H.W.; SOTER, N. A. (Orgs.). Clinical photomedicine. New York: Marcel Dekker Inc., 1993, p. 19-35.

4. APFELBERG, D. B.; SNIKKERM, B. Ultrapulse carbon dioxide laser with CPG scanner for deepithelialization: clinical and histologic study. Plast Reconstr Surg, v. 99, p. 2089-94, 1997.

5. AUERSVAULD, A. Estudo experimental em ratos da ablação da pele em laser $\mathrm{CO}_{2}$ ultrapulsado. 1999. Dissertação (Mestrado em Princípios da Cirurgia) - Faculdade Evangélica de Medicina do Paraná, Hospital Universitário Evangélico de Curitiba, Curitiba.

6. AYRES, S. I. I. I. Superficial dermosurgery. Its current status and its relation to dermabrasion. Arch Dermatol, v. 89, n. 4: 395 403, 1964

7. BURKHARDT, B. R.; MAW, R. Are more passes better? Safety versus efficacy with the pulsed $\mathrm{CO}_{2}$ laser. Plast Reconstr Surg, n. 100, p. 1531-34, 1997.

8. CARNIOL, P. J.; HANKE, C. W.; DAVID, L. M. Erbium:YAG laser resurfacing. In: Carniol, P.J. Laser skin rejuvenation. Philadelphia: Lippincot-Raven, 1998, p. 26I-9.

9. CHAMON,W. Estudo clínico sobre ceratectomia fototerapêutica com Excimer laser de fluoreto de argônio (193mm). 1995. Tese (Doutorado em Medicina) - Escola Paulista de Medicina, Universidade Federal de São Paulo, São Paulo.

10. DAVID, L. M.; LASK, G. P.; GLASSBERG, E.; JACOBY, R.; ABERGEL, R. P. Laser abrasion for cosmetic and medical treatment of facial actinic damage. Cutis Belle Mead, v. 43 , n. 6, p. 583-7, 1989

I I. DERMA TM20 ER:YAG: superior technology. DermaTM20 Er: YAG, application notes, v. 4, p. I-4, 1997 (I).
12. DERMATM20 ER:YAG: a technological leap in skin rejuvenation. Derma TM20 Er:YAG, application notes, v. 4, p. I-4, 1997 (2).

13. FTZPATRICK, R. E.; TOPE, W. D.; GOLDMAN, M. P.; SATUR, N. M. Pulsed carbon dioxide laser, trichloroacetic acid, Baker-Gordon phenol, and dermabrasion: comparative clinical and histologic study of cutaneous resurfacing in a porcine model. Arch Dermatol, v. I 32, n. 4, p. 45।-5, 1996.

14. FRANÇA, A. L. F. Estudo histopatológico das lesões causadas por duas e quatro passadas de laser de Erbium:YAG com 0\% de sobreposição de spots, em dorso de ratos. 1999. Dissertação (Mestrado em Clínica Cirúrgica) - Setor de Ciências da Saúde, Universidade Federal do Paraná, Curitiba.

15. GOLDBERG, D. J. Erbium:YAG laser resurfacing: what is its role? Aesthetic Surg J, v. I8, n. 4, p. 255-60, 1998.

16. GOLDBERG, D. J.; MEINE, J.G. Treatment of photoaged neck skin with the pulsed Erbium:YAG laser. Dermatol Surg, v. 24, p. 619-21, 1998

17. GOLDMAN, M. P.; MANUSKIATTI, W. Combined laser resurfacing with the $950-\mu \mathrm{sec}$ pulsed $\mathrm{CO}_{2}+$ Er:YAG lasers. Dermatol Surg, v. 25, p. 160-3, 1999.

18. GRAF, R. Estudo da contração cutânea após o uso do laser Erbium: YAG em ratos. 2000. Dissertação (Mestrado em Princípios da Cirurgia) - Faculdade Evangélica de Medicina do Paraná, Hospital Universitário Evangélico de Curitiba, Curitiba.

19. GREGORY, R. O. Laser physics and physiology. Clinics in Plastic Surgery, v. 24, p. 89-93, 1998.

20. HALLOCK, G. G.; RICE, D. C. Comparison of the contact neodymium: YAG and carbon dioxide lasers for skin deepithelialization. Plast Reconstr Surg, v. 91, n. 6, p. I I34-9, I 993.

2I. HERD, R. M.; DOVER, J. S.; ARNDT, K. Basic laser principles. Dermatol Clin, v. I5, n. 3, p. 355-72, 1997.

22. HIBST, R.; KAUFMANN, R. Effects of laser parameters on pulsed Er:YAG laser skin ablation. Lasers Med Sci, v. 6, p. 39|-7, |99|. 
23. HOHENLEUTNER, U.; HOHENLEUTNER, S.; ELÄUMLER,W:; LANDTHALER, M. Fast and effective skin ablation with an Er:YAG laser: determination of ablation rates and thermal damage zones. Lasers Surg Med, v. 20, p. 242-7, 1997.

24. HUGHES, P. S. H. Skin contraction following Erbium :YAG laser resurfacing. Dermatol Surg, v. 24, p. 109-1।, 1998.

25. JAFFE, B. H.;WALSH, J.T.J. R. Water flux from partial-thickness skin wounds: comparative study of the effects of Er:YAG and Ho:YAG lasers. Lasers Surg Med, v. I8, n. I, p. I-9, 1996.

26. KAUFMANN, R.; HARTMANN, A.; HIBST, R. Cutting and skinablative properties of pulsed mid-infrared laser surgery. J Dermatol Surg Oncol, v. 20, p. 1 12-8, 1994.

27. KAUFMANN, R.; HIBST, R. Pulsed Erbium:YAG laser ablation in cutaneous surgery. Lasers Surg Med, v. 19, n. 3, p. 324-30, 1996.

28. MOLGAT, Y. M.; POLLACK, S. V.; HURWITZ, J. J.; BUNAS, S. J.; MANNIN,T.; MCCORMACK, K. M.; PINNELL, S. R. Comparative study of wound healing in porcine skin with $\mathrm{CO}_{2}$ laser and other surgical modalities: preliminary findings. Int J Dermatol, v. 34, n. I, p. 42-7, 1995.

29. NANNI, C. A.; ALSTER, T. S. Complications of cutaneous laser surgery. A review. Dermatol Surg, v. 24, n. 2, p. 209-19, 1998.

30. NORONHA, L.; AUERSVALD, A.; MARTINS, V. D. M.; BERNARDES, A.; GRAF, R. Estudo comparativo das alterações histológicas imediatas causadas pelo uso de lasers $\mathrm{CO}_{2}$ e de erbium na pele de ratos wistar.Jornal Brasileiro de Patologia, v. 37, 200 I (I).

3I. NORONHA, L.; CHIN, E.W. K.; MENINI, C. M.; KNOPLHOLZ, J.; RAMPAZZO, J. C. R.; GRAF, R. Histopathologic and morphometric evaluation of the skin abnormalities induced by Erbium:Yag carbon dioxide lasers in 10 patients. Plastic Reconstr Surg, v. 108, p. 1380-88, 2001.

32. NORONHA, L.; GRAF, R.; KANNENBERG, C.; BELLINI, P. A; PELLEGRINELLO, S.; VROBLESWKI, T. V. Alterações histopatológicas causadas pela aplicação de laser $\mathrm{CO}_{2}$ em pele humana para fins de rejuvenescimento. Arquivos de Medicina, v. 4, p. I79-83, 2001.

33. PEREZ, M. I.; BANK, D. E.; SILVERS, D. Skin resurfacing of the face with the Erbium:YAG laser. Dermatol Surg, v. 24, n. 6: p. 653-8, 1998.
34. RODRIGUES, R. G.; RIBAS, J. M.; MALAFAIA, O.; NIGRO, C. C.; ARAÚjO,L.R.R. Estudo comparativo da influência da aplicação do laser $\mathrm{CO}_{2}$ ultrapulsado na sobrevivência de retalho cutâneo dorsal em ratos. Acta Cir Bras, v. 4, p. 39-40, 1999.

35. ROSS, E.V.; DOMANKEVITZ,Y.; SKROBAL, M.;ANDERSON, R. $\mathrm{R}$. Effects of $\mathrm{CO}_{2}$ laser pulse duration in ablation and residual thermal damage: implications for skin resurfacing. Lasers Surg Med, v. 19, p. 123-9, 1996.

36. ROSS, E. V.; YASHAR, S. S.; NASEEF, G. S.; BARNETTE, D. J.; SKROBAL, M.; GREVENLINK, J.; ANDERSON, R. R. A pilot study of in vivo immediate tissue contraction. Lasers Surg Med, v. 24, p. I33-141, 1999.

37. RUBACH, B.W.; SCHOENROCK, L. D. Histological and clinical evaluation of facial resurfacing using a carbon dioxide laser with the computer pattern generator. Arch Otolaryngol Head Neck Surg, v. 123, p. 929-34, 1997.

38. SECKEL, B. R.; YOUNAI, S.;WANG, K-K. Skin tightening effects of the ultrapulse $\mathrm{CO}_{2}$ laser. Plast Reconst Surg, v. 102, p. 872-7, 1998.

39. STUZIN, J. M.; BAKER, T. J.; BAKER, T. M.; KLIGMAN, A. M. Communications in cosmetic surgery. Plast Reconstr Surg, v. 99, p. 2036-50, 1997.

40. TRELLES, M. A.; DAVID, L. M.; RIGAU, J. Penetration depth of ultrapulse carbon dioxide laser in human skin. Dermatol Surg, v. 22, p. 863-5, 1996.

4I. WALSH, J. R.; DEUTSCH, T. Er:YAG laser ablation of tissue: measurement of ablation rates. Laser Surg Med, v. 9, p. 327-37, 1989.

42. WALSH, J. R.; FLOTTE, T. J.; DEUTSCH, T. F. Er:YAG laser ablation of tissue: effect of pulse duration and tissue type on thermal damage. Laser Surg Med, v. 9, p. 314-26, 1989.

43. WEINSTEIN, C. Computerized scanning Erbium:YAG laser for skin resurfacing. Dermatol Surg, v. 24, p. 83-9, 1998.

44.WEINSTEIN, C. Erbium laser resurfacing: current concepts. Plast Reconstr Surg, v. 103, p. 603-18, 1999.

45. WEISS, R. A.; HARRINGTON, A. C.; PFAU, R. C.; WEISS, M. A.; MARWAHA, S. Periorbital skin resurfacing using high energy Erbium:YAG laser: results in 50 patients. Lasers Surg Med, v. 24, p. 8I-6, 1999.

46. YANG, C. C.; CHAl, C.Y. Animal study of skin resurfacing using the ultrapulse carbon dioxide laser. Ann Plast Surg, v. 35, p. $154-8,1995$.
Endereço para correspondência

Lúcia de Noronha Pontifícia Universidade Católica do Paraná - Campus I Centro de Ciências Biológicas e da Saúde Laboratório de Patologia Experimental Rua Imaculada Conceição, 1.155 - Prado Velho CEP: 80215-901 - Curitiba-PR

Tel.: (41) 330-1515 - Ramal: 2493

Fax: (41) 330-1621 e-mail: Inno@terra.com.br 